Vietnam Journal of Mechanics, VAST, Vol.34, No. 1 (2012), pp. $27-44$

\title{
NONLINEAR ANALYSIS OF BUCKLING AND POSTBUCKLING FOR AXIALLY COMPRESSED FUNCTIONALLY GRADED CYLINDRICAL PANELS WITH THE POISSON'S RATIO VARYING SMOOTHLY ALONG THE THICKNESS
}

\author{
Dao Van Dung, Le Kha Hoa \\ Hanoi University of Science, VNU
}

\begin{abstract}
In this paper an approximate analytical solution to analyze the nonlinear buckling and postbuckling behavior of imperfect functionally graded panels with the Poisson's ratio also varying smoothly along the thickness is investigated. Based on the classical shell theory and von Karman's assumption of kinematic nonlinearity and applying Galerkin procedure, the equations for finding critical loads and load-deflection curves of cylindrical panel subjected to axial compressive load with two types boundary conditions, are given. Especially, the stiffness coefficients are analyzed in explicit form. Numerical results show various effects of the inhomogeneous parameter, dimensional parameter, boundary conditions on nonlinear stability of panel. An accuracy of present theoretical results is verified by the previous well-known results.
\end{abstract}

Keywords: Nonlinear, Postbuckling, Functionally graded materials, Cylindrical panel.

\section{INTRODUCTION}

Functionally graded structures such as cylindrical panels and cylindrical shells in recent years play the important part in the modern industries [1]. They are lightweight structures and are able to withstand high-temperature environments while maintaining their structural integrity. Therefore, researches on stability problems of functionally graded materials (FGMs) structures have received considerable attention. Some investigations on postbuckling of FGM cylindrical panels and cylindrical shells subjected to axial loading or pressure loading in thermal environments are presented by Shen and Noda [2, 3]. They employed singular perturbation techniques to determine the buckling loads and postbuckling equilibrium paths. Chang and Librescu [4] reported postbuckling of shear deformable flat and curved panels under combined loading conditions. The problem on structural stability of functionally graded panels subjected to aero-thermal loads is considered by Sohn and Kim [5]. The studies involving postbuckling of laminated cylindrical panels loaded by improved arc-length method can be found in the paper of Kweon and Hong [6]. Wilde et al. [7] presented investigation on critical state of an axially compressed cylindrical panel with 
three edges simply supported and one edge free. Huang and Taucher [8] solved the problem on large deflection of laminated cylindrical and doubly-curved panels under thermal loading. By different methods, the authors Dennis et al. [9], Yamada and Croll [10], investigated instability, buckling behavior of pressure loaded cylindrical panels. Kabir and Chaudhur [11] presented a direct Fourier approach for the analysis of thin finite-dimensional cylindrical panels. Thermomechanical postbuckling of FGM cylindrical panels with temperature dependent properties is investigated by Yang et al. [12]. Geometrically nonlinear analysis of functionally graded shells are considered by Zhao and Liew [13]. Alijani and Aghdam [14], by applying the extended Kantorovich method, given a semi-analytical solution for stress analysis of moderately thick laminated cylindrical panels with various boundary conditions.

In the field of dynamic buckling of FGM structures, Sofiyev [15], Huang and Han [16], Ng et al. [17], Bich and Long [18], Dung and Nam [19] presented nonlinear dynamic

buckling and postbuckling analysis of FGM shallow and cylindrical shells subjected to various loadings.

However, analytical investigations on nonlinear analysis of FGM cylindrical shells and panels under mechanical or thermal loading are limited in number, so it is necessary to be more accelerated in this area. Recently, the results on the nonlinear analysis of stability for functionally graded cylindrical panels under axial compression have been obtained by Duc and Tung [20]. They presented an analytical approach to obtain explicit expressions of buckling load and postbuckling load-deflection curves in the case Poisson's ratio $\nu$ being constant and boundary conditions being simply supported.

When Poisson's ratio $\nu$ depends on thickness $z$, there exists some investigations of Huang and Han $[21,22,23]$. These authors touched upon the problem on nonlinear buckling and postbuckling of imperfect functionally graded closed circular cylindrical shells subjected to different mechanical and thermal loadings with $\nu=\nu(z)$ in the power law of $z$, but the stiffness coefficients $A_{i j}$ being still defined in the integrating form, not yet analyzed. Therefore, an aim of this present research is to extend the results of [20] considering Young's modulus $E=E(z)$ and Poisson's ratio $\nu=\nu(z)$, simultaneously for calculating and giving the stiffness coefficients $A_{i j}$ of $[21,22,23]$ in explicit form. Based on the classical shell theory and geometrical nonlinearity in von Karman sense, the approximate analytical solutions have been presented. The resulting equations are solved by Galerkin's procedure to obtain equations for finding critical loads and postbuckling load-deflection curves with two types of boundary conditions. In the case $\nu$ is a constant, the reached results return to ones of [20].

\section{FUNCTIONALLY GRADED CYLINDRICAL PANELS AND FUNDAMENTAL RELATIONS}

\subsection{Functionally graded cylindrical panels}

Let us consider a FGM cylindrical panel with uniform thickness $h$, mean radius $R$ and length of straight edge $a$, of curved edge $b$. We choose a cylindrical coordinate $(x, y=R \theta, z)$ so that the axes $\mathrm{x}, \mathrm{y}$ are in the longitudinal, circumferential directions 
respectively and axe $z$ is perpendicular to the middle surface and in the inward thickness direction $(-h / 2 \leq z \leq h / 2)$ (see Fig. 1). The cylindrical panel is subjected to the uniform

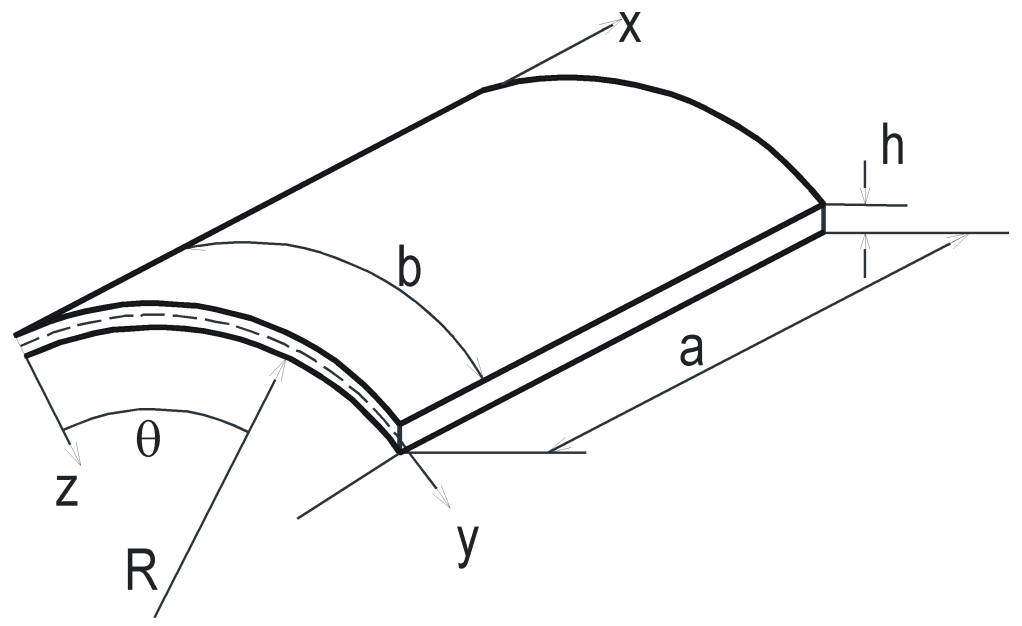

Fig. 1. FGM cylindrical panels

plane compressive loads of intensities $r_{0}$ on $x=0, x=a$ and $p_{0}$ on $y=0, y=b$ and an uniform radial load of intensity $Q_{0}$.

Assume that material properties vary through the thickness $z$ with the power law as follows [21]

$$
\begin{gathered}
E=E(z)=E_{m}+\left(E_{c}-E_{m}\right)\left(\frac{2 z+h}{2 h}\right)^{k} \equiv E_{m}+E_{c m} r^{k} \\
\nu=\nu(z)=\nu_{m}+\left(\nu_{c}-\nu_{m}\right)\left(\frac{2 z+h}{2 h}\right)^{k_{1}} \equiv \nu_{m}+\nu_{c m} r^{k_{1}}
\end{gathered}
$$

in which

$$
E_{c m}=E_{c}-E_{m}, \quad r=\frac{2 z+h}{2 h}, \quad \nu_{c m}=\nu_{c}-\nu_{m}, \quad k \geq 0, k_{1} \geq 0 .
$$

The quantities $E_{m}, E_{c}$ and $\nu_{m}, \nu_{c}$ are Young's moduli and Poisson's ratios of metal (m) and ceramic (c), respectively.

\subsection{Governing relations and equations}

The strain components on the middle surface of imperfect cylindrical panel based upon the von Karman's theory are [21]

$$
\begin{aligned}
& \varepsilon_{x}^{0}=u_{, x}+\frac{1}{2} w_{, x}^{2}+w_{, x} w_{, x}^{*}, \\
& \varepsilon_{y}^{0}=v_{, y}-\frac{w}{R}+\frac{1}{2} w_{, y}^{2}+w_{, y} w_{, y}^{*}, \\
& \gamma_{x y}^{0}=u_{, y}+v_{, x}+w_{, x} w_{, y}+w_{, x} w_{, y}^{*}+w_{, y} w_{, x}^{*} .
\end{aligned}
$$


where $u=u(x, y), v=v(x, y), w=w(x, y)$ are the displacements along $x, y$ and $z$ axes respectively. The quantity $w^{*}=w^{*}(x, y)$ is an initial imperfection of panel and assumed smaller than thickness of panel.

The strain components across the panel thickness at a distance $z$ from the mid-plane are in the form

$$
\begin{aligned}
& \varepsilon_{x}=\varepsilon_{x}^{0}+z k_{x}, \quad \varepsilon_{y}=\varepsilon_{y}^{0}+z k_{y}, \quad \gamma_{x y}=\gamma_{x y}^{0}+2 z k_{x y}, \\
& k_{x}=-w_{, x x}, \quad k_{y}=-w_{, y y}, \quad k_{x y}=-w_{, x y} .
\end{aligned}
$$

Note that the subscript $A_{, i}$ in this paper indicates the partial derivative of $A$ for $i$.

The stress-strain relationships of cylindrical panel are defined by Hookian law, as

$$
\left(\sigma_{x}, \sigma_{y}\right)=\frac{E}{1-\nu^{2}}\left[\left(\varepsilon_{x}, \varepsilon_{y}\right)+\nu\left(\varepsilon_{y}, \varepsilon_{x}\right)\right], \quad \sigma_{x y}=\frac{E}{2(1+\nu)} \gamma_{x y} .
$$

The force and moment resultants are expressed by

$$
\left\{\left(N_{x}, N_{y}, N_{x y}\right),\left(M_{x}, M_{y}, M_{x y}\right)\right\}=\int_{-h / 2}^{h / 2}\left\{\sigma_{x}, \sigma_{y}, \sigma_{x y}\right\}(1, z) d z .
$$

Substituting Eqs $(4) \div(6)$ into (7), we get

$$
\left[\begin{array}{c}
N_{x} \\
N_{y} \\
N_{x y} \\
M_{x} \\
M_{y} \\
M_{x y}
\end{array}\right]=\left[\begin{array}{cccccc}
A_{10} & A_{20} & 0 & A_{11} & A_{21} & 0 \\
A_{20} & A_{10} & 0 & A_{21} & A_{11} & 0 \\
0 & 0 & A_{30} & 0 & 0 & A_{31} \\
A_{11} & A_{21} & 0 & A_{12} & A_{22} & 0 \\
A_{21} & A_{11} & 0 & A_{22} & A_{12} & 0 \\
0 & 0 & A_{31} & 0 & 0 & A_{32}
\end{array}\right]\left[\begin{array}{c}
\varepsilon_{x}^{0} \\
\varepsilon_{y}^{0} \\
\gamma_{x y}^{0} \\
k_{x} \\
k_{y} \\
2 k_{x y}
\end{array}\right]
$$

where the stiffness coefficients $A_{i j} \quad(i=1,2,3 ; j=0,1,2)$ are defined by the formulae

$$
\begin{aligned}
A_{1 j} & =\int_{-h / 2}^{h / 2} \frac{E(z)}{1-\nu^{2}(z)} z^{j} d z, \quad A_{2 j}=\int_{-h / 2}^{h / 2} \frac{E(z) \nu(z)}{1-\nu^{2}(z)} z^{j} d z, \\
A_{3 j} & =\int_{-h / 2}^{h / 2} \frac{E(z)}{2[1+\nu(z)]} z^{j} d z=\frac{1}{2}\left(A_{1 j}-A_{2 j}\right) .
\end{aligned}
$$

The explicit analytical expressions of $A_{i j}$ are calculated and given in the Appendix. The equilibrium equations of imperfect cylindrical panel are derived from [21]

$$
\begin{gathered}
N_{x, x}+N_{x y, y}=0, \\
N_{x y, x}+N_{y, y}=0, \\
M_{x, x x}+2 M_{x y, x y}+M_{y, y y}+\frac{N_{y}}{R}+N_{x}\left(w_{, x x}+w_{, x x}^{*}\right)+ \\
+2 N_{x y}\left(w_{, x y}+w_{, x y}^{*}\right)+N_{y}\left(w_{, y y}+w_{, y y}^{*}\right)+Q_{0}=0 .
\end{gathered}
$$


The geometrical compatibility equation deduced from (4) and (5), assuming $w_{, i j}^{*}$ small so the quadratic terms of $w_{, i j}^{*}$ may be omitted, becomes

$$
\begin{aligned}
\varepsilon_{x, y y}^{0}+\varepsilon_{y, x x}^{0}-\gamma_{x y, x y}^{0}=-\frac{1}{R} w_{, x x}+w_{, x y}^{2}-w_{, x x} \cdot w_{, y y} & +2 w_{, x y} w_{, x y}^{*}- \\
& -w_{, x x} \cdot w_{, y y}^{*}-w_{, y y} w_{, x x}^{*}
\end{aligned}
$$

Introducing Airy's stress function $f=f(x, y)$ so that

$$
N_{x}=f_{, y y}, \quad N_{y}=f_{, x x}, \quad N_{x y}=-f_{, x y} .
$$

It is easy seen that two equations (10), (11) are automatically satisfied.

Substituting these functions (14) into $N_{i j}$ of relations (8) and solving conversely, we obtain

where

$$
\begin{aligned}
\varepsilon_{x}^{0} & =J_{0}\left(A_{10} f_{, y y}-A_{20} f_{, x x}+J_{1} w_{, x x}+J_{2} w_{, y y}\right) \\
\varepsilon_{y}^{0} & =J_{0}\left(A_{10} f_{, x x}-A_{20} f_{, y y}+J_{1} w_{, y y}+J_{2} w_{, x x}\right) \\
\gamma_{x y}^{0} & =\frac{1}{A_{30}}\left(2 A_{31} w_{, x y}-f_{, x y}\right)
\end{aligned}
$$

$$
J_{0}=\frac{1}{A_{10}^{2}-A_{20}^{2}}, \quad J_{1}=A_{10} A_{11}-A_{20} A_{21}, \quad J_{2}=A_{10} A_{21}-A_{20} A_{11} .
$$

Substituting once again Eq. (15) into the expressions of $M_{i j}$ in (8), then $M_{i j}$ into the equation (12) and taking into account (14), leads to

$$
\begin{aligned}
C_{3} \nabla^{4} f+\frac{1}{R} f_{, x x}+C_{4} \nabla^{4} w+f_{, y y}\left(w_{, x x}+w_{, x x}^{*}\right) & -2 f_{, x y}\left(w_{, x y}+w_{, x y}^{*}\right) \\
& +f_{, x x}\left(w_{, y y}+w_{, y y}^{*}\right)+Q_{0}=0
\end{aligned}
$$

where

$$
\begin{aligned}
C_{3} & =J_{0} J_{2}, \quad C_{4}=J_{0}\left(A_{11} J_{1}+A_{21} J_{2}\right)-A_{12}, \\
\nabla^{4} & =\frac{\partial^{4}}{\partial x^{4}}+2 \frac{\partial^{4}}{\partial x^{2} \partial y^{2}}+\frac{\partial^{4}}{\partial y^{4}} .
\end{aligned}
$$

The equation (17) includes two unknowns functions $w$ and $f$, so it is necessary to find a second equation relating to these two functions. For this aim, substituting expression (15) into the compatible equation (13), after some calculations, we get

$$
\nabla^{4} f+C_{1} \nabla^{4} w-C_{2}\left(w_{, x y}^{2}-w_{, x x} w_{, y y}-\frac{w_{, x x}}{R}+2 w_{, x y} w_{, x y}^{*}-w_{, x x} w_{, y y}^{*}-w_{, y y} w_{, x x}^{*}\right)=0
$$

where $C_{1}=\frac{J_{2}}{A_{10}}, C_{2}=\frac{1}{J_{0} A_{10}}$.

Two equations (17) and (18) are the governing equations used to investigate the nonlinear stability of imperfect FGM cylindrical panels.

\section{Remarks}

i) If $R \rightarrow \infty$, the equations (17) and (18) return to the basic stability equations for imperfect FGM plates.

ii) In the case $w^{*}=0$, from (17) and (18) we obtain the governing equations for perfect cylindrical panels. 
iii) Eqs. (15), (17) and (18) are similar to ones of [21], but the stiffness coefficients $A_{i j}$, in this paper, are analyzed in the explicit form.

iv) If $\nu=$ const, Eqs.(17) and (18) coincide with ones of [20].

\section{BOUNDARY CONDITIONS AND SOLUTION OF THE PROBLEM}

\subsection{Boundary conditions}

Suppose that two cases boundary conditions will be considered below

Case (1). Four edges of cylindrical panel are simply supported

$$
\begin{array}{lllll}
w=M_{x}=N_{x y}=0, & N_{x}=-r_{0} h & \text { at } & x=0, & x=a \\
w=M_{y}=N_{x y}=0, & N_{y}=-p_{0} h & \text { at } & y=0, & y=b
\end{array}
$$

Case (2). Two edges loaded $x=0$ and $x=a$ are simply supported, the remaining two edges $y=0, y=b$ being unloaded and clamped. So we have

$$
\begin{aligned}
& w=M_{x}=N_{x y}=0, \quad N_{x}=-r_{0} h \quad \text { at } \quad x=0, \quad x=a \\
& w=\frac{\partial w}{\partial y}=N_{y}=N_{x y}=0 \quad \text { at } \quad y=0, \quad y=b .
\end{aligned}
$$

\subsection{Solving for FGM cylindrical panel with simply supported four edges}

Based on mentioned boundary conditions (19), the deflection $w$ and function $f$ are chosen in the form $[20]$

$$
w=W \sin \frac{m \pi x}{a} \sin \frac{n \pi y}{b}, \quad f=F\left[\sin \frac{m \pi x}{a} \sin \frac{n \pi y}{b}-\theta(x)-\lambda(y)\right],
$$

in which $F \frac{d^{2} \theta(x)}{d x^{2}}=p_{0} h, \quad F \frac{d^{2} \lambda(y)}{d y^{2}}=r_{0} h, \quad m, n=1,2,3, \ldots$

For the initial imperfection $w^{*}=w^{*}(x, y)$, we assume it has the form like the deflection $w$, i.e.

$$
w^{*}=\xi h \sin \frac{m \pi x}{a} \sin \frac{n \pi y}{b}, \quad m, n=1,2,3, \ldots
$$

where the coefficient $\xi \in[0,1]$ expresses an imperfection size of panel.

Now substituting Eqs. (21) and (22) into Eqs. (17) and (18) and applying Galerkin's procedure, leads to nonlinear algebraic two equations for $F$ and $W$ as

$$
\begin{aligned}
& F=-C_{1} W+\frac{C_{2} W}{R\left[\left(\frac{m \pi}{a}\right)^{2}+\left(\frac{n \pi}{b}\right)^{2}\right]^{2}}\left[\left(\frac{m \pi}{a}\right)^{2}-\frac{16 R m n \pi^{2}}{3 a^{2} b^{2}}(W+2 \xi h) \delta_{1} \delta_{2}\right], \\
& {\left[\left(\frac{m \pi}{a}\right)^{2}+\left(\frac{n \pi}{b}\right)^{2}\right]^{2}\left(C_{3} F+C_{4} W\right)+F\left[\frac{32}{3}(W+\xi h) \frac{m n \pi^{2}}{a^{2} b^{2}} \delta_{1} \delta_{2}-\frac{1}{R}\left(\frac{m \pi}{a}\right)^{2}\right]+} \\
& +(W+\xi h)\left[r_{0} h\left(\frac{m \pi}{a}\right)^{2}+p_{0} h\left(\frac{n \pi}{b}\right)^{2}\right]+\frac{16}{m n \pi^{2}} \delta_{1} \delta_{2}\left[Q_{0}-\frac{p_{0} h}{R}\right]=0 .
\end{aligned}
$$

Herein, note that $\delta_{1}=\frac{1}{2}\left[1-(-1)^{m}\right], \delta_{2}=\frac{1}{2}\left[1-(-1)^{n}\right]$, so $\delta_{1} \delta_{2}=1$ if $m$ and $n$ being odd numbers while $\delta_{1} \delta_{2}=0$ if $\mathrm{m}$ or $\mathrm{n}$ even. 
By eliminating $F$ in Eqs. (23), (24), after some calculations we obtain

$$
\begin{aligned}
& {\left[\left(C_{4}-C_{3} C_{1}\right) \pi^{4}\left(m^{2} B_{a}^{2}+n^{2}\right)^{4}+\frac{\left(C_{1}+C_{2} C_{3}\right)}{R}\left(m \pi b B_{a}\right)^{2}\left(m^{2} B_{a}^{2}+n^{2}\right)^{2}-\right.} \\
& \left.-\frac{C_{2}\left(m b B_{a}\right)^{4}}{R^{2}}\right] W-\frac{16 m n \pi^{2} B_{a}^{2}}{3}\left(m^{2} B_{a}^{2}+n^{2}\right)^{2}\left[\left(C_{2} C_{3}+2 C_{1}\right) W+2\left(C_{2} C_{3}+\right.\right. \\
& \left.\left.+C_{1}\right) \times \xi h\right] W \delta_{1} \delta_{2}+\frac{16 m^{3} n b^{2} B_{a}^{4}}{3 R} C_{2} W(3 W+4 \xi h) \delta_{1} \delta_{2}-\frac{512 m^{2} n^{2} B_{a}^{4}}{9} C_{2} W \times \\
& \times(W+\xi h)(W+2 \xi h) \delta_{1}^{2} \delta_{2}^{2}+\pi^{2} b^{2} r_{0} h\left(m^{2} B_{a}^{2}+n^{2}\right)^{2}\left(m^{2} B_{a}^{2}+\beta n^{2}\right)(W+\xi h)+ \\
& \quad+\frac{16 b^{4}}{m n \pi^{2}}\left(m^{2} B_{a}^{2}+n^{2}\right)^{2}\left[Q_{0}-\frac{\beta r_{0} h}{R}\right] \delta_{1} \delta_{2}=0
\end{aligned}
$$

where $B_{a}=b / a, \quad \beta=p_{0} / r_{0}$.

The equation (25) establishes the relation of load-deflection, so it is used to analyze buckling and postbuckling behavior of imperfect FGM cylindrical panels subjected to loads $r_{0}, p_{0}$ and $Q_{0}$.

Since the aim of present study is only to consider cylindrical panel subjected to axial compressive load, thus taking $N_{x 0}=-r_{0} h, N_{y 0}=-p_{0} h=0, Q_{0}=0$, Eq. (25) yields

$$
\begin{aligned}
& r_{0}=\frac{\bar{W}}{(\bar{W}+\xi)}\left[\frac{\pi^{2}\left(m^{2} B_{a}^{2}+n^{2}\right)^{2}}{B_{h}^{2} m^{2} B_{a}^{2}}\left(\bar{D}+\bar{C}_{3} \bar{C}_{1}\right)-\frac{\left(\overline{C_{1}}+\overline{E_{1}} h^{2} \overline{C_{3}}\right)}{R}+\frac{\overline{E_{1}} R_{a}^{2} m^{2} B_{a}^{4}}{\pi^{2}\left(m^{2} B_{a}^{2}+n^{2}\right)^{2}}\right] \\
& +\frac{16 n h}{3 b^{2} m} \frac{\bar{W}}{(\bar{W}+\xi)}\left[\left(\overline{E_{1}} h^{2} \overline{C_{3}}+2 \bar{C}_{1}\right) \bar{W}+2\left(\overline{E_{1}} h^{2} \overline{C_{3}}+\bar{C}_{1}\right) \xi\right] * \delta_{1} \delta_{2}- \\
& -\frac{16 m n R_{a} B_{a}^{3} \overline{E_{1}}}{3 \pi^{2} B_{h}\left(m^{2} B_{a}^{2}+n^{2}\right)^{2}} \frac{\bar{W}(3 \bar{W}+4 \xi)}{(\bar{W}+\xi)} \delta_{1} \delta_{2}+\frac{512 n^{2} B_{a}^{2} \overline{E_{1}}}{9 \pi^{2} B_{h}^{2}\left(m^{2} B_{a}^{2}+n^{2}\right)^{2}} \bar{W}(\bar{W}+2 \xi) \delta_{1}^{2} \delta_{2}^{2},
\end{aligned}
$$

where

$$
\begin{aligned}
& \bar{D}=-\frac{C_{4}}{h^{3}}, \quad \overline{E_{1}}=\frac{C_{2}}{h}, \quad B_{h}=\frac{b}{h}, \\
& R_{a}=\frac{a}{R}, \quad \bar{W}=\frac{W}{h}, \quad \overline{C_{1}}=\frac{C_{1}}{h}, \quad \overline{C_{3}}=\frac{C_{3}}{h^{2}} .
\end{aligned}
$$

For a perfect cylindrical panel $(\xi=0)$ subjected to only axial compressive load $r_{0}$, Eq. (24) leads to

$$
\begin{aligned}
& r_{0}=\frac{\pi^{2}\left(m^{2} B_{a}^{2}+n^{2}\right)^{2}}{B_{h}^{2} m^{2} B_{a}^{2}}\left(\bar{D}+\bar{C}_{3} \bar{C}_{1}\right)-\frac{\left(\overline{C_{1}}+\overline{E_{1}} h^{2} \overline{C_{3}}\right)}{R}+\frac{\overline{E_{1}} R_{a}^{2} m^{2} B_{a}^{4}}{\pi^{2}\left(m^{2} B_{a}^{2}+n^{2}\right)^{2}}+\frac{16 n h}{3 b^{2} m} \times \\
& \times\left(\overline{E_{1}} h^{2} \overline{C_{3}}+2 \bar{C}_{1}\right) \bar{W} \delta_{1} \delta_{2}-\frac{16 m n R_{a} B_{a}^{3} \overline{E_{1}}}{\pi^{2} B_{h}\left(m^{2} B_{a}^{2}+n^{2}\right)^{2}} \bar{W} \delta_{1} \delta_{2}+\frac{512 n^{2} B_{a}^{2} \overline{E_{1}}}{9 \pi^{2} B_{h}^{2}\left(m^{2} B_{a}^{2}+n^{2}\right)^{2}} \overline{W^{2}} \delta_{1}^{2} \delta_{2}^{2}
\end{aligned}
$$


from which upper buckling compressive load may be obtained with $W \rightarrow 0$ as

$$
r_{0} \text { upper }=\frac{\pi^{2}\left(m^{2} B_{a}^{2}+n^{2}\right)^{2}}{B_{h}^{2} m^{2} B_{a}^{2}}\left(\bar{D}+\bar{C}_{3} \bar{C}_{1}\right)-\frac{\left(\overline{C_{1}}+\overline{E_{1}} h^{2} \overline{C_{3}}\right)}{R}+\frac{\overline{E_{1}} R_{a}^{2} m^{2} B_{a}^{4}}{\pi^{2}\left(m^{2} B_{a}^{2}+n^{2}\right)^{2}} .
$$

Note that the relation (29) may also be deduced from Eq. (28) with $m$ or $n$ being even numbers.

Now we are interested in finding a lower buckling load. For that, consider $r_{0}=r_{0}(\bar{W})$ and $m, n$ odd numbers and calculating $\frac{d r_{0}}{d \bar{W}}=0$ we get

$$
\bar{W}_{\mathrm{th}}=\frac{9 m R_{a} B_{h} B_{a}}{64 n}-\frac{3 \pi^{2} B_{h}\left(m^{2} B_{a}^{2}+n^{2}\right)^{2}}{64 b m n B_{a}^{2} \overline{E_{1}}}\left(\overline{E_{1}} h^{2} \overline{C_{3}}+2 \bar{C}_{1}\right) .
$$

In addition $\left.\frac{d^{2} r_{0}}{d \bar{W}^{2}}\right|_{\bar{W}=\bar{W}_{\text {th }}}>0$, the value of lower buckling load is

$$
\begin{aligned}
& r_{\text {Olower }}=\frac{\pi^{2}\left(m^{2} B_{a}^{2}+n^{2}\right)^{2}}{B_{h}^{2} m^{2} B_{a}^{2}}\left(\bar{D}+\bar{C}_{3} \bar{C}_{1}\right)-\frac{\left(\overline{C_{1}}+\overline{E_{1}} h^{2} \overline{C_{3}}\right)}{R}+\frac{\overline{E_{1}} R_{a}^{2} m^{2} B_{a}^{4}}{\pi^{2}\left(m^{2} B_{a}^{2}+n^{2}\right)^{2}}+ \\
& +\frac{3 R_{a} B_{h} B_{a} h}{4 b^{2}} \times\left(\overline{E_{1}} h^{2} \overline{C_{3}}+2 \bar{C}_{1}\right)-\frac{\pi^{2} h B_{h}\left(m^{2} B_{a}^{2}+n^{2}\right)^{2}}{4 b^{3} m^{2} B_{a}^{2} \overline{E_{1}}}\left(\overline{E_{1}} h^{2} \overline{C_{3}}+2 \bar{C}_{1}\right)^{2}- \\
& -\frac{9 m^{2} R_{a}^{2} B_{a}^{4} \overline{E_{1}}}{4 \pi^{2}\left(m^{2} B_{a}^{2}+n^{2}\right)^{2}}+\frac{3 R_{a} B_{a}}{4 b}\left(\overline{E_{1}} h^{2} \overline{C_{3}}+2 \bar{C}_{1}\right)+ \\
& +\frac{B_{a}^{2} \overline{E_{1}}}{8 \pi^{2}\left(m^{2} B_{a}^{2}+n^{2}\right)^{2}}\left[3 m R_{a} B_{a}-\frac{\pi^{2}\left(m^{2} B_{a}^{2}+n^{2}\right)^{2}}{b m B_{a}^{2} \overline{E_{1}}}\left(\overline{E_{1}} h^{2} \overline{C_{3}}+2 \bar{C}_{1}\right)\right]^{2}
\end{aligned}
$$

Quantities $r_{0 u p p e r}$ and $r_{0 l o w e r}$ given by (29) and (30) still depend on values of $m$ and $n$, therefore one must minimize these expressions with respect to $m$ and $n$ to obtain critical values of axial compressive load.

\section{Remarks}

i) If Poisson's ratio $\nu=$ const, i.e. $k_{1}=0, m, n$ are odd numbers and $N_{x}=-r_{0} h$, $Q_{0}=0, N_{y}=-p_{0} h=0$ then $\bar{C}_{1}=\bar{C}_{3}=0$.

Eq. (24) becomes

$$
\begin{aligned}
r_{0}= & \frac{\bar{W}}{(\bar{W}+\xi)}\left[\frac{\bar{D} \pi^{2}\left(m^{2} B_{a}^{2}+n^{2}\right)^{2}}{B_{h}^{2} m^{2} B_{a}^{2}}+\frac{\overline{E_{1}} R_{a}^{2} m^{2} B_{a}^{4}}{\pi^{2}\left(m^{2} B_{a}^{2}+n^{2}\right)^{2}}\right]- \\
& -\frac{16 m n R_{a} B_{a}^{3} \overline{E_{1}}}{3 \pi^{2} B_{h}\left(m^{2} B_{a}^{2}+n^{2}\right)^{2}} \frac{\bar{W}(3 \bar{W}+4 \xi)}{(\bar{W}+\xi)}+\frac{512 n^{2} B_{a}^{2} \overline{E_{1}}}{9 \pi^{2} B_{h}^{2}\left(m^{2} B_{a}^{2}+n^{2}\right)^{2}} \bar{W}(\bar{W}+2 \xi)
\end{aligned}
$$

ii) If $\nu=$ const, $\xi=0$ and $m, n$ odd numbers then Eq. (28) gives us

$$
\begin{aligned}
r_{0}= & \frac{\bar{D} \pi^{2}\left(m^{2} B_{a}^{2}+n^{2}\right)^{2}}{B_{h}^{2} m^{2} B_{a}^{2}}+\frac{\overline{E_{1}} R_{a}^{2} m^{2} B_{a}^{4}}{\pi^{2}\left(m^{2} B_{a}^{2}+n^{2}\right)^{2}} \\
& -\frac{16 m n R_{a} B_{a}^{3} \overline{E_{1}}}{\pi^{2} B_{h}\left(m^{2} B_{a}^{2}+n^{2}\right)^{2}} \bar{W}+\frac{512 n^{2} B_{a}^{2} \overline{E_{1}}}{9 \pi^{2} B_{h}^{2}\left(m^{2} B_{a}^{2}+n^{2}\right)^{2}} \bar{W}^{2} .
\end{aligned}
$$


Taking $\bar{W} \rightarrow 0$ then Eq. (32) gives the upper buckling load for a perfect panel

$$
r_{0}=\frac{\bar{D} \pi^{2}\left(m^{2} B_{a}^{2}+n^{2}\right)^{2}}{B_{h}^{2} m^{2} B_{a}^{2}}+\frac{\overline{E_{1}} R_{a}^{2} m^{2} B_{a}^{4}}{\pi^{2}\left(m^{2} B_{a}^{2}+n^{2}\right)^{2}} .
$$

Eqs. (31), (32) and (33) coincide with ones given in the paper [20].

iii) If cylindrical panel is perfect and isotropic and $\bar{W} \rightarrow 0$ then

$$
\begin{aligned}
& E_{1}=E h, \quad E_{2}=0, \quad E_{3}=\frac{E h^{3}}{12}, \quad \overline{E_{1}}=\frac{E_{1}}{h}=E, \\
& \bar{D}=\frac{E_{1} E_{3}-E_{2}^{2}}{E_{1}\left(1-\nu^{2}\right) h^{3}}=\frac{E}{12\left(1-\nu^{2}\right)} .
\end{aligned}
$$

Noting $B_{a}=\frac{b}{a}, B_{h}=\frac{b}{h}, R_{a}=\frac{a}{R}$, Eq. (33) leads to

$$
r_{0}=\frac{E \pi^{2}\left(m^{2} \frac{b^{2}}{a^{2}}+n^{2}\right)^{2} a^{2} h^{2}}{12\left(1-\nu^{2}\right) b^{4} m^{2}}+\frac{E b^{4} m^{2}}{\pi^{2} R^{2} a^{2}\left(m^{2} \frac{b^{2}}{a^{2}}+n^{2}\right)^{2}} .
$$

The minimum value of $r_{0}$, in this case, is

$$
r_{0 c r}=\frac{E h}{R \sqrt{3\left(1-\nu^{2}\right)}} .
$$

This is result can be found in [24].

\subsection{Solving for FGM cylindrical panel with simply supported loaded two edges and clamped unloaded two edges}

Suppose a FGM cylindrical panel is only subjected to uniform axial compressive load of intensity $r_{0}$ on $x=0, x=a$ and uniform compressive radial load of intensity $Q_{0}$. Two edges $y=0, y=b$ are clamped and unloaded, while the remaining two edges are simply supported.

In this case, the approximate solutions satisfying boundary conditions (20) are follow as

$$
\begin{aligned}
& w=W \sin \frac{m \pi x}{a}\left(1-\cos \frac{2 n \pi y}{b}\right) \\
& f=F\left[\sin \frac{m \pi x}{a} \sin \frac{n \pi y}{b}-\lambda(y)\right], \quad F \lambda^{\prime \prime}(y)=r_{0} h \\
& w^{*}=\xi h \sin \frac{m \pi x}{a}\left(1-\cos \frac{2 n \pi y}{b}\right), \quad m, n=1,2,3, \ldots
\end{aligned}
$$

By the same method in the part 3.2, we substitute Eq. (36) into left side of Eqs. (17) and (18), and then apply Galerkin's procedure, we get

$$
F=\frac{1}{A}\left\{-W \frac{4 C_{1}}{3 n \pi} \delta_{2}\left[3\left(\frac{m \pi}{a}\right)^{4}+B\right]+C_{2}\left[\frac{W}{R} \frac{16 m^{2} \pi}{3 n a^{2}} \delta_{2}-W(W+2 \xi h) \frac{1024 m n \pi^{2}}{45 a^{2} b^{2}} \delta_{1} \delta_{2}\right]\right\},
$$




$$
\begin{aligned}
& {\left[C_{3} A-\frac{1}{R}\left(\frac{m \pi}{a}\right)^{2}\right] } \frac{4 a b}{3 n \pi} \delta_{2} F+C_{4} W \frac{a b}{4}\left[2\left(\frac{m \pi}{a}\right)^{4}+B\right]+F(W+\xi h)\left(\frac{m n \pi^{2}}{a b}\right)^{2} \times \\
& \times \frac{512 a b}{45 m n \pi^{2}} \delta_{1} \delta_{2}+r_{0} h(W+\xi h)\left(\frac{m \pi}{a}\right)^{2} \frac{3 a b}{4}+Q_{0} \frac{2 a b}{m \pi} \delta_{1}=0
\end{aligned}
$$

where $A=\left[\left(\frac{m \pi}{a}\right)^{2}+\left(\frac{n \pi}{b}\right)^{2}\right]^{2}, B=\left[\left(\frac{m \pi}{a}\right)^{2}+\left(\frac{2 n \pi}{b}\right)^{2}\right]^{2}$.

Eliminating $F$ in Eqs. (37) and (38), leads to

$$
\begin{aligned}
\alpha_{1} W+\alpha_{2} W(W+2 \xi h)+\alpha_{3} W(W & +\xi h)+\alpha_{4} W(W+\xi h)(W+2 \xi h)+ \\
& +r_{0} h(W+\xi h) \frac{3 b m^{2} \pi^{2}}{4 a}+\frac{2 a b}{m \pi} \delta_{1} Q_{0}=0
\end{aligned}
$$

in which

$$
\begin{aligned}
& \alpha_{1}=\left[C_{3}-\frac{1}{R A}\left(\frac{m \pi}{a}\right)^{2}\right]\left\{-\frac{16 a b C_{1}}{9 n^{2} \pi^{2}} \delta_{2}^{2}\left[3\left(\frac{m \pi}{a}\right)^{4}+B\right]+\frac{64 m^{2} b C_{2}}{9 n^{2} a R} \delta_{2}^{2}\right\}+ \\
& \alpha_{2}=-\left[C_{3}-\frac{1}{R A}\left(\frac{m \pi}{a}\right)^{2}\right] \frac{4096 m \pi C_{4}}{135 a b}\left[2\left(\frac{m \pi}{a}\right)_{1}^{4}+B\right], \\
& \alpha_{3}=\left\{-\frac{2048 m \pi C_{1}}{135 a b A}\left[3\left(\frac{m \pi}{a}\right)^{4}+B\right]+\frac{8192 m^{3} \pi^{3} C_{2}}{135 a^{3} b R A}\right\} \delta_{1} \delta_{2}^{2}, \\
& \alpha_{4}=-\frac{524288 m^{2} n^{2} \pi^{4} C_{2}}{2025 a^{3} b^{3} A}\left(\delta_{1} \delta_{2}\right)^{2} .
\end{aligned}
$$

Now, consider the case $Q_{0}=0$, i.e. the panel only is subjected to axial compressive load, from Eq. (39), deduces

$$
r_{0}=\frac{-4 a}{3 b m^{2} \pi^{2}}\left[\alpha_{1} \frac{\bar{W}}{h(\bar{W}+\xi)}+\alpha_{2} \frac{\bar{W}(\bar{W}+2 \xi)}{(\bar{W}+\xi)}+\alpha_{3} \bar{W}+\alpha_{4} h \bar{W}(\bar{W}+2 \xi)\right] .
$$

Herein denote $\bar{W}=W / h$.

If a cylindrical panel is perfect $(\xi=0)$, Eq. (41) becomes

$$
r_{0}=\frac{-4 a}{3 b m^{2} \pi^{2}}\left[\frac{\alpha_{1}}{h}+\left(\alpha_{2}+\alpha_{3}\right) \bar{W}+\alpha_{4} h \bar{W}^{2}\right] .
$$

From this relation, let $\bar{W} \rightarrow 0$, we obtain the expression of upper buckling compressive load as

$$
\begin{aligned}
& r_{\text {oupper }}=\frac{-4 a}{3 b m^{2} \pi^{2} h} \alpha_{1}=\left[C_{3}-\frac{1}{R A}\left(\frac{m \pi}{a}\right)^{2}\right] \times \\
& \times\left\{\frac{64 a^{2} C_{1}}{27 m^{2} n^{2} \pi^{4} h} \delta_{2}^{2}\left[3\left(\frac{m \pi}{a}\right)^{4}+B\right]-\frac{256 C_{2}}{27 n^{2} \pi^{2} R h} \delta_{2}^{2}\right\}-\frac{a^{2} C_{4}}{3 m^{2} \pi^{2} h}\left[2\left(\frac{m \pi}{a}\right)^{4}+B\right]
\end{aligned}
$$


In order to find a lower buckling compressive load, from (42) calculate $\frac{d r_{0}}{d \bar{W}}=0$, it is easy to receive

$$
\bar{W}_{\mathrm{th}}=\frac{-\left(\alpha_{2}+\alpha_{3}\right)}{2 \alpha_{4} h} .
$$

In addition $\left.\frac{d^{2} r_{0}}{d \bar{W}^{2}}\right|_{\bar{W}=\bar{W}_{\text {th }}}>0$, so yields to

$$
r_{\text {Olower }}=\frac{-4 a}{3 b m^{2} \pi^{2}}\left[\frac{\alpha_{1}}{h}-\frac{\left(\alpha_{2}+\alpha_{3}\right)^{2}}{4 \alpha_{4} h}\right] .
$$

\section{NUMERICAL CALCULATIONS AND DISCUSSIONS}

The FGMs considered, in this section, are made from two constituent materials: Stainless steel (SUS304) and Silicon nitride $\left(\mathrm{Si}_{3} \mathrm{~N}_{4}\right)$ with the properties given by Shariyat $[25] \mathrm{E}_{c}=322.2(\mathrm{GPa}), \mathrm{E}_{m}=207.7(\mathrm{GPa}), \nu_{\mathrm{c}}=0.24, \nu_{\mathrm{m}}=0.3177$.

The accuracy of proposed approach and effects of dimensional parameters, of power law indexes $k$ and $k_{1}$, of imperfection and boundary conditions on buckling and postbuckling behavior are presented by numerical results.

For the sake of simplifying calculations $A_{i j}$, the sum in Appendix taken values from 0 to 5 .

As a first example, the buckling load $N_{x} /(E R), N_{x}=r_{0} h, r_{0}$ given by Eq. (34) for isotropic cylindrical panels under axial compression (with $\nu=0.3$ ) studied by Turvey (1977) and Shen (2002) in [2] are reexamined and are compared in Table 1.

Table 1. Comparisons of buckling load $N_{x} /(E R)$ for isotropic cylindrical panels

\begin{tabular}{|c|c|c|c|c|}
\hline & \multicolumn{4}{|c|}{ Calculated by } \\
\hline Geometrical parameters & Turvey & Shen & Present & Percent (\%) \\
\hline $\begin{array}{c}\mathrm{a} / \mathrm{b}=0.4, \mathrm{a} / \mathrm{R}=1.0 \\
\mathrm{~b} / \mathrm{h}=25\end{array}$ & $0.73675 \mathrm{e}-4$ & $\begin{array}{c}0.71410 \mathrm{e}-4 \\
(\mathrm{~m}, \mathrm{n})=(3,1)\end{array}$ & $\begin{array}{c}0.77355 \mathrm{e}-4 \\
(\mathrm{~m}, \mathrm{n})=(3,1)\end{array}$ & 4.99 \\
\hline $\begin{array}{c}\mathrm{a} / \mathrm{b}=1.333, \mathrm{a} / \mathrm{R}=1.0, \\
\mathrm{~b} / \mathrm{h}=75\end{array}$ & $0.60523 \mathrm{e}-4$ & $\begin{array}{c}0.58737 \mathrm{e}-4 \\
(\mathrm{~m}, \mathrm{n})=(2,2)\end{array}$ & $\begin{array}{c}0.60756 \mathrm{e}-4 \\
(\mathrm{~m}, \mathrm{n})=(2,2)\end{array}$ & 0.38 \\
\hline
\end{tabular}
under axial compression

The axial buckling loads $P_{c r}=r_{0 u p p e r} b h, r_{0 u p p e r}$ in Eq. (29), for perfect $\mathrm{Si}_{3} \mathrm{~N}_{4}-$ SUS304 cylindrical panels with different values of volume fraction indexes $k$ and $k_{1}$ are given and compared with results of Shen [2] in Table 2.

Two above comparisions show that the results from the present proposed method agree well with the comparator solutions.

For further examples see below, the graphs from Fig. 2 to Fig. 7 are traced according to Eq.(26) for simply supported panels and Eq.(41) for clamped panels respectively.

As part of the effects of imperfections, the postbuckling load-deflection curves for FGM cylindrical panels shown in Fig. 2a and Fig. 2b. As can be observed, when the deflection exceeds a specific value, the curves become higher when $\xi$ is increased. 
Table 2. Comparisons of buckling loads $P_{c r}$ of perfect FGM simply supported cylindrical panels

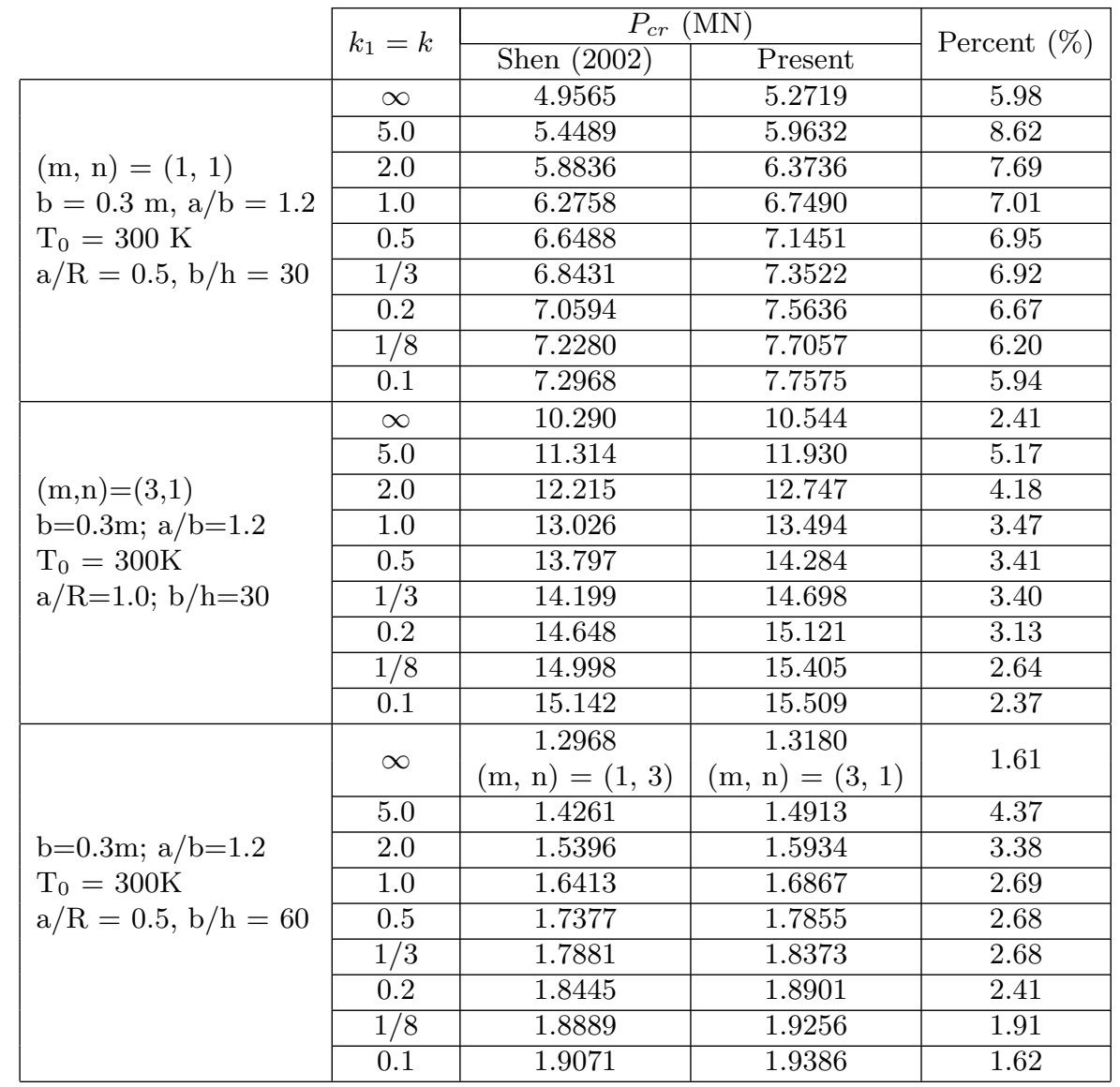

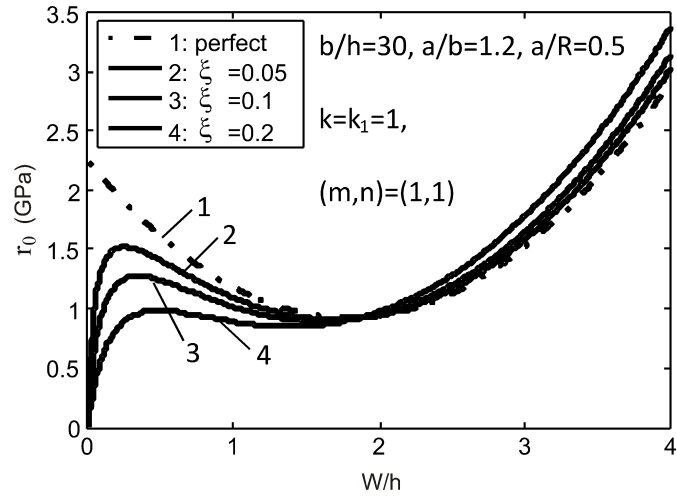

(a) For simply supported FGM cylindrical panels

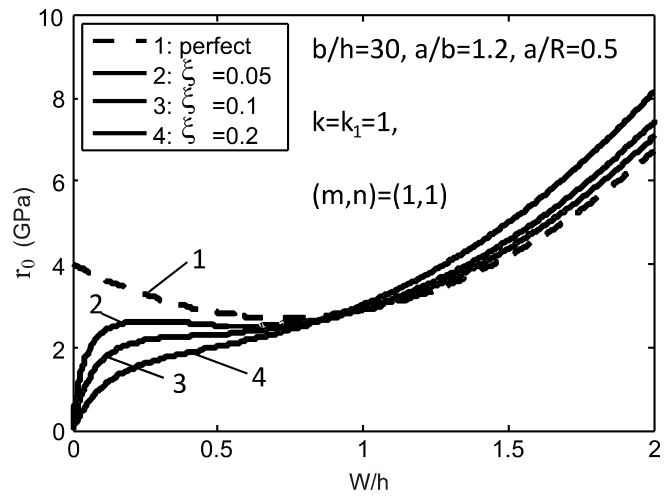

(b) For FGM cylindrical panels with two edges simply supported and two edges clamped

Fig. 2. Effects of imperfection $\xi$ on postbuckling load-deflection curves 
Fig. 3a and Fig. 3b illustrate the effects of volume fraction indexes $k$ and $k_{1}$. Three values of $k=k_{1}=0,1,5$ are used. As shown, the postbuckling load-deflection curves are gradually lower when the values of $k=k_{1}$ increase, i.e. the load carrying capacity of structure decreases with the greater percentage of metal. The prime reason for the fall of the critical loads is that the higher value of $k$ corresponds to a metal-richer cylindrical panel which usually has less stiffness than a ceramic-richer one.

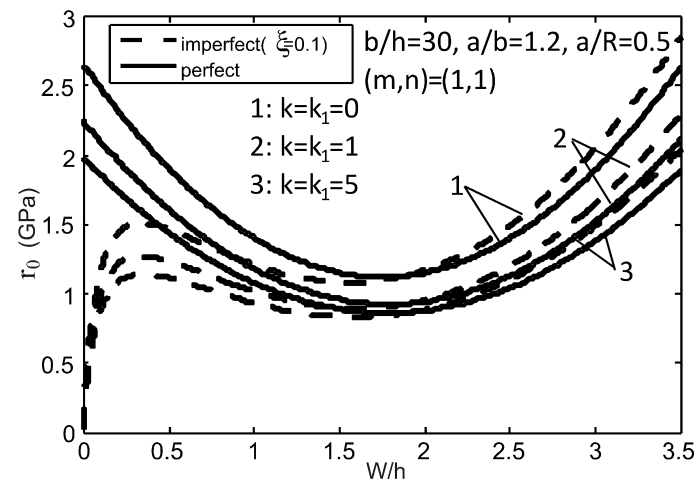

(a) For simply supported FGM cylindrical panels

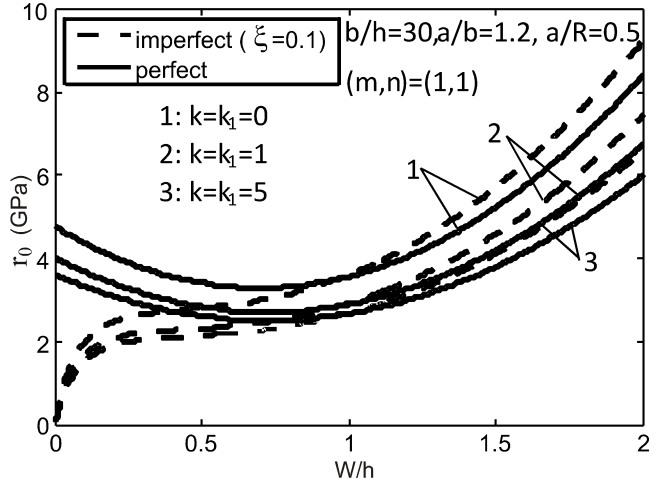

(b) For FGM cylindrical panels with two edges simply supported and two edges clamped

Fig. 3. Effects of volume fraction indexes $k$ and $k_{1}$ on postbuckling load-deflection curves

For the effects of geometrical parameters, the numerical calculations are manifested by graph below

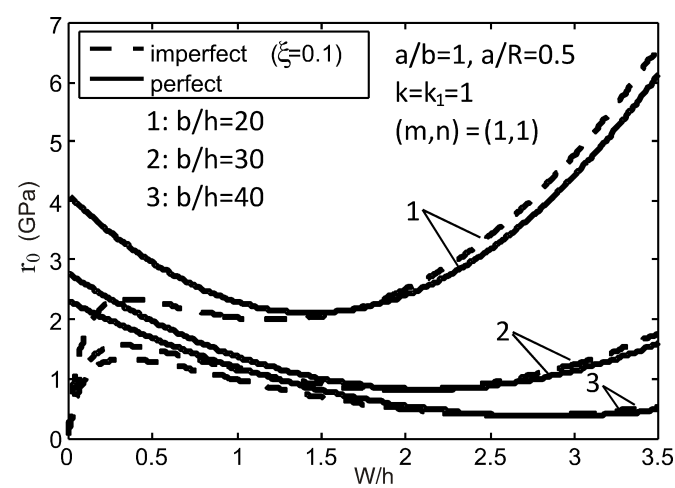

(a) For simply supported FGM cylindrical panels

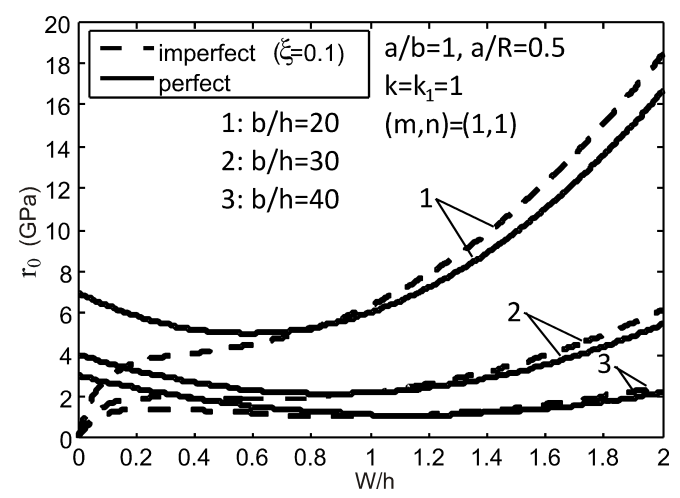

(b) For clamped FGM cylindrical panels

Fig. 4. Effects of ratio $b / h$ on postbuckling load-deflection curves

Fig. 4. plots relation curves load-deflection versus width-to-thickness ratio $b / h$ with $k=k_{1}=1, \xi=0, \xi=0.1$. 


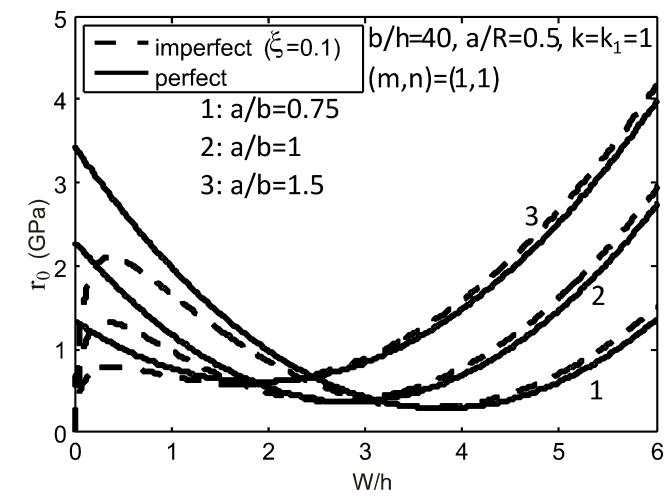

(a) For simply supported FGM cylindrical panels

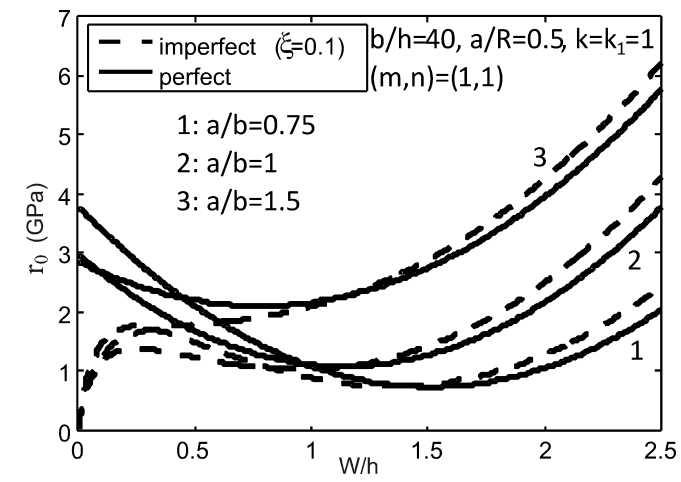

(b) For clamped FGM cylindrical panels

Fig. 5. Effects of ratio $a / b$ on postbuckling load-deflection curves

Fig. 5. plots these relation curves versus length-to-width ratio $a / b$ with $k=k_{1}=1$, $\xi=0, \xi=0.1$.

Fig. 6. shows the effect of length-to-radius ratio $a / R$ on $\left(W / h, r_{0}\right)$ relation curves. It is obvious, from these figures, that the buckling loads and postbuckling load bearing

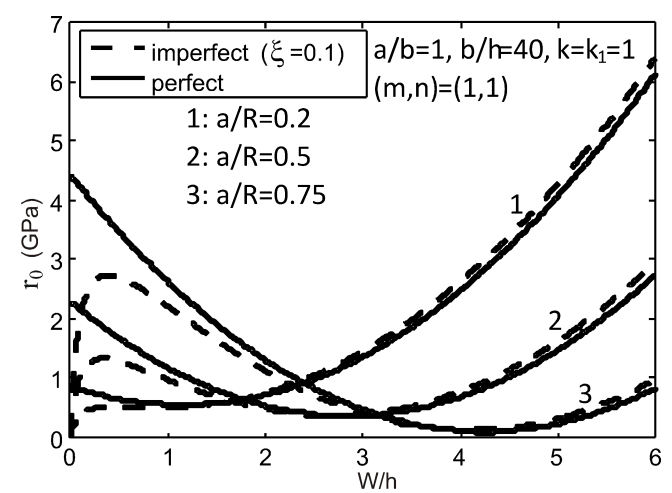

(a) For simply supported FGM cylindrical panels

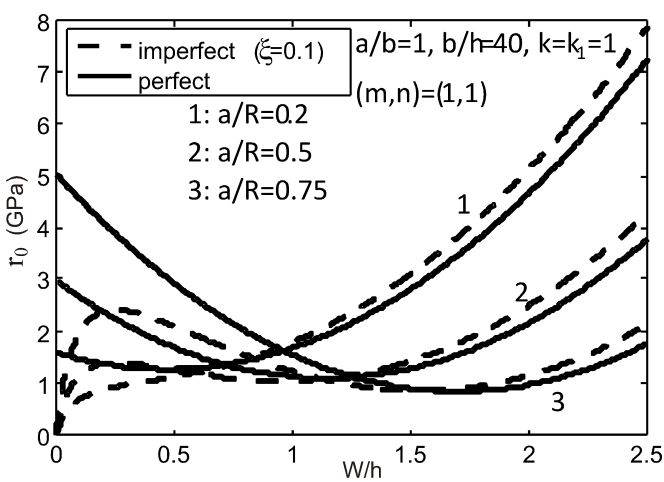

(b) For clamped FGM cylindrical panels

Fig. 6. Effects of ratio $a / R$ on postbuckling load-deflection curves

capacity of imperfect FGM cylindrical panels are considerably reduced when $b / h$ ratios increase (Fig. 4). The values of $r_{0}$ when the deflection is still small, are decrease when $a / b$ increase, and they only increase together $a / b$ when $W / h$ ratio exceeds special value (Fig. $5)$. In Fig. 6 , can be seen that the $\left(W / h, r_{0}\right)$ relation curves graduate higher according to $a / R$ with $W / h$ being still small and they become gradually lower when the $W / h$ ratios are greater than a any special value. 
The influence of two types boundary conditions on stability behavior has been also carried out. The numerical results are represented by graph in Fig. 7 (a, b, c). It can be seen that the critical buckling loads when panels are simply supported, are smaller than ones when those structures are clamped. These results correspond to the facts.

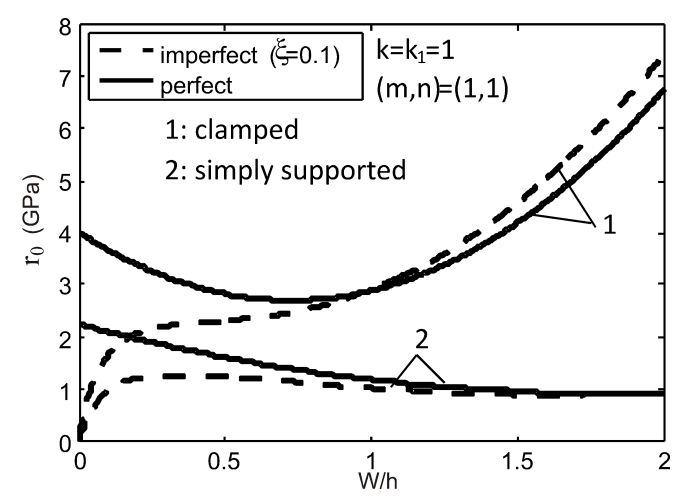

(a) For FGM cylindrical panels with $a / b=1.2$, $b / h=30, a / R=0.5$

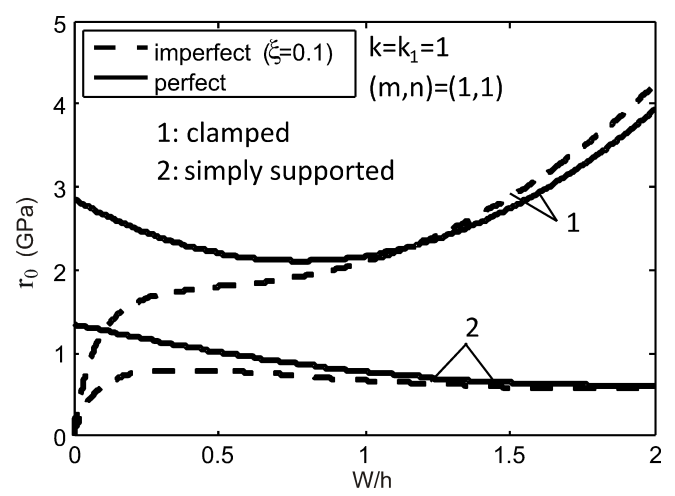

(b) For FGM cylindrical panels with $a / b=1.5$, $b / h=40, a / R=0.5$

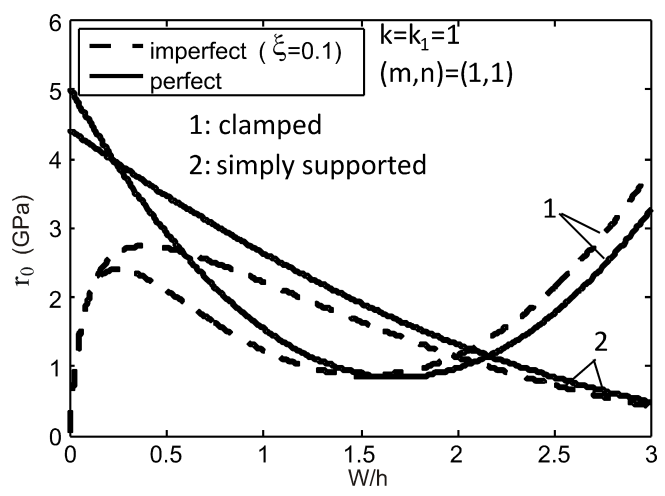

(c) For FGM cylindrical panels with $a / b=1$, $b / h=40, a / R=0.75$

Fig. 7. Effects of boundary conditions on postbuckling load-deflection curves

The influence of boundary conditions, indexes $k$ and $k_{1}$, buckling mode $(m, n)$ on critical loads $r_{\text {Oupper }}$ and $r_{\text {Olower }}$ for imperfect FGM cylindrical panel with $b / h=30, a / b$ $=1.2, a / R=0.5$, again are confirmed by numerical calculation in Table 3 .

For this example, it can be seen that the critical buckling loads of simply supported FGM cylindrical panels correspond to the buckling mode $(m, n)=(1,1)$, while the critical buckling loads of clamped FGM panels reached with $(\mathrm{m}, \mathrm{n})=(3,1)$. 
Table 3. The influence of boundary conditions, of indexes $k$ and $k_{1}$, of buckling mode $(\mathrm{m}, \mathrm{n})$ on critical loads $r_{0 c r}$

\begin{tabular}{|c|c|c|c|c|c|}
\hline $\begin{array}{l}\text { Boundary } \\
\text { conditions }\end{array}$ & $r_{0 c r}(\mathrm{Gpa})$ & $(\mathrm{m}, \mathrm{n})=(1,1)$ & $(\mathrm{m}, \mathrm{n})=(1,3)$ & $(\mathrm{m}, \mathrm{n})=(3,1)$ & $(\mathrm{m}, \mathrm{n})=(3,3)$ \\
\hline \multirow{8}{*}{$\begin{array}{l}\text { Simply } \\
\text { supported }\end{array}$} & $r_{\text {Oupper }}\left(k_{1}=k=0\right)$ & 2.6632 & 42.335 & 3.3023 & 11.781 \\
\hline & $r_{\text {Oupper }}\left(k_{1}=k=0.5\right)$ & 2.3817 & 37.073 & 2.9357 & 10.348 \\
\hline & $r_{\text {Oupper }}\left(k_{1}=k=10\right)$ & 1.9046 & 31.241 & 2.4179 & 8.7018 \\
\hline & $r_{\text {Oupper }}\left(k_{1}=k=\infty\right)$ & 1.7573 & 28.611 & 2.2109 & 7.9575 \\
\hline & $r_{\text {Olower }}\left(k_{1}=k=0\right)$ & 1.1207 & 42.288 & 2.5439 & 11.609 \\
\hline & $r_{\text {Olower }}\left(k_{1}=k=0.5\right)$ & 0.9733 & 36.970 & 2.2184 & 10.146 \\
\hline & $r_{\text {Olower }}\left(k_{1}=k=10\right)$ & 0.8337 & 31.178 & 1.8779 & 8.5583 \\
\hline & $r_{\text {Olower }}\left(k_{1}=k=\infty\right)$ & 0.7627 & 28.581 & 1.7220 & 7.8470 \\
\hline \multirow{8}{*}{$\begin{array}{l}\text { Simply } \\
\text { supported } \\
x=0, x=a \\
\text { Clamped } \\
y=0, y=b\end{array}$} & $r_{\text {Oupper }}\left(k_{1}=k=0\right)$ & 4.7677 & 202.13 & 3.7008 & 31.070 \\
\hline & $r_{\text {Oupper }}\left(k_{1}=k=0.5\right)$ & 4.2414 & 176.76 & 3.2834 & 27.176 \\
\hline & $r_{\text {Oupper }}\left(k_{1}=k=10\right)$ & 3.4704 & 149.05 & 2.7130 & 22.913 \\
\hline & $r_{\text {Oupper }}\left(k_{1}=k=\infty\right)$ & 3.1813 & 136.61 & 2.4811 & 20.999 \\
\hline & $r_{\text {Olower }}\left(k_{1}=k=0\right)$ & 3.2858 & 20.212 & 2.9723 & 31.052 \\
\hline & $r_{\text {Olower }}\left(k_{1}=k=0.5\right)$ & 2.8558 & 176.73 & 2.5926 & 27.150 \\
\hline & $r_{\text {Olower }}\left(k_{1}=k=10\right)$ & 2.4239 & 149.03 & 2.1933 & 22.895 \\
\hline & $r_{\text {Olower }}\left(k_{1}=k=\infty\right)$ & 2.2259 & 136.61 & 2.0114 & 20.987 \\
\hline
\end{tabular}

\section{CONCLUSIONS}

This paper deals with the nonlinear buckling and postbuckling problem of axially compressed imperfect FGM cylindrical panels by using the nonlinear deflection shell theory taking into account the Poisson's ratio $\nu=\nu(z)$. The stiffness coefficients $A_{i j}$ defined in the integrating form in $[21,22,23]$ are analyzed in explicit form.

Approximate analytical solutions for two types boundary conditions are given and applying Galerkin's procedure are obtained the explicit relations finding critical buckling loads and postbuckling load-deflection curves.

The nonlinear stability problem of simply supported-clamped FGM cylindrical panels which has not been considered in [20] is solved too here.

The effects of inhomogeneous parameter, dimensional parameter, boundary conditions, initial imperfections, buckling mode on nonlinear stability behavior of FGMs cylindrical panels are investigated.

The comparisions of results of present paper with the ones other authors $[2,20,24]$ have affirmed the reliability and accuracy of the proposed approach.

In the case $\nu=$ const, the present results return to ones of [20].

In this paper, we does not compare results with these ones of $[21,22,23]$ because those articles were only considered for the FGM closed circular cylindrical shell while our results are obtained for FGM cylindrical panels.

\section{REFERENCES}

[1] Koizumi M., FGM activities Japan, Composite Part B: Engineering, 28 (1997) 1 - 4.

[2] Shen H. S., Postbuckling analysis of axially loaded functionally graded cylindrical panels in thermal environments, Int J Solids and Struct, 39 (2002) 5991 - 6010. 
[3] Shen H. S., Noda N., Postbuckling of FGM cylindrical shells under combined axial and radial mechanical loads in thermal environments, Int J Solids and Struct, 42 (2005) 4641 - 4662.

[4] Chang M. Y., Librescu L., Postbuckling of shear deformable flat and curved panels under combined loading conditions, Int J Mech Sci, 37 (1995) 121 - 143.

[5] Sohn K. J., Kim J. H., Structural stability of functionally graded panels subjected to aerothermal loads, Compos Struct, 82 (2008) 317 - 325.

[6] Kweon J. H., Hong C. S., An improved arc-length method for post-buckling analysis of composite cylindrical panel, Comput and Struct, 53 (1994) 541 - 549.

[7] Wilde R., Zawodny P., Magnucki K., Critical state of an axially compressed cylindrical panel with three edges simply supported and one edge free, Thin-Walled Struct, 45 (2007) 955 - 959.

[8] Huang N. N., Taucher T. R., Large deflection of laminated cylindrical and doubly-curved panels under thermal loading, Comput and Struct, 41 (1991) 303 - 312.

[9] Dennis S. T., Horban B. A., Palazotto A. N., Instability in a cylindrical panel subjected to normal pressure: Bifurcation vs nonlinear analysis, Compos Eng, 4(6) (1994) 605 - 620.

[10] Yamada S., Croll J. G. A., Buckling behavior of pressure loaded cylindrical panels, J Eng Mech, 115(2) (1989) 327 - 344.

[11] Kabir H. R. H., Chaudhur R. A., A direct Fourier approach for the analysis of thin finitedimensional cylindrical panels, Comput and Struct, 46(2) (1993) 279 - 287.

[12] Yang Y., Liew K. M., Wu Y. F., Kitipornchai S., Thermo-mechanical postbuckling of FGM of FGM cylindrical panels with temperature dependent properties, Int J Solids and Struct, 43 (2006) $307-324$.

[13] Zhao X., Liew K. M., Geometrically nonlinear analysis of functionally graded shells, Int $J$ Mech Sci, 51 (2009) 131 - 144.

[14] Alijani F., Aghdam M. M., A semi-analytical solution for stress analysis of moderately thick laminated cylindrical panels with various boundary conditions, Compos Struct, 89 (2009) 543 -550 .

[15] Sofiyev A. H., The stability of compositionally graded ceramic-metal cylindrical shells under aperiodic axial impulsive loading, Compos Struct, 69 (2005) 247 - 257.

[16] Huang H., Han Q., Nonlinear dynamic buckling of functionally graded cylindrical shells subjected to a time-dependent axial load, Compos Struct, 92 (2010) 593 - 598.

[17] Ng T. Y., Lam K.Y., Liew K. M., Reddy J. N., Dynamic stability analysis of functionally graded cylindrical shells under periodic axial loading, Int J Solids Struct, 38 (2001) 1295 1309.

[18] Bich D. H., Long V. D., Nonlinear dynamical analysis of imperfect FGM shallow shells, Vietnam J Mech, 32 (2010) 1 - 14.

[19] Dung D. V., Nam V. H., Nonlinear dynamic analysis of imperfect FGM shallow shells with simply supported and clamped boundary conditions, Proceedings of the tenth National Conference on Deformable Solid Mechanics, Thai Nguyen, (2010) 130 - 141.

[20] Duc N. D., Tung H. V., Nonlinear analysis of stability for functionally graded cylindrical panels under axial compression, Comput Mater Sci, 49 (2010) 313 - 316.

[21] Huang H., Han Q., Buckling of imperfect functionally graded cylindrical shells under axial compression, European J Mech A/Solids, 27 (2008) 1026 - 1036.

[22] Huang H., Han Q., Research on nonlinear postbuckling of functionally graded cylindrical shells under radial loads, Compos Struct, 92 (2010) 1352 - 1357.

[23] Huang H., Han Q., Nonlinear buckling of torsion-loaded functionally graded cylindrical shells in thermal environment, European J Mech A/Solids, 29 (2010) 42 - 48. 
[24] Brush D. O., Almroth B. O., Buckling of bars, plates and shells, New York: Mc Graw-Hill, (1975).

[25] Shariyat M., Dynamic thermal buckling of suddenly heated temperature-dependent FGM cylindrical shells under combined axial compression and external pressure, Int $J$ Solids and struct, 45 (2008) 2598 - 2612.

Received March 9, 2011

\section{APPENDIX}

$$
\begin{aligned}
& A_{10}=\frac{h}{2} \sum_{n \geq 0}\left(\frac{E_{m}}{n k_{1}+1}+\frac{E_{c m}}{k+n k_{1}+1}\right) c_{n} \\
& A_{11}=\frac{h^{2}}{2} \sum_{n>0}\left[E_{m}\left(\frac{1}{n k_{1}+2}-\frac{1}{2\left(n k_{1}+1\right)}\right)+E_{c m}\left(\frac{1}{k+n k_{1}+2}-\frac{1}{2\left(k+n k_{1}+1\right)}\right)\right] c_{n} \\
& A_{12}=\frac{h^{3}}{2} \sum_{n \geq 0}\left[E_{m}\left(\frac{1}{n k_{1}+3}-\frac{1}{n k_{1}+2}+\frac{1}{4\left(n k_{1}+1\right)}\right)\right. \\
& \left.+E_{c m}\left(\frac{1}{k+n k_{1}+3}-\frac{1}{k+n k_{1}+2}+\frac{1}{4\left(k+n k_{1}+1\right)}\right)\right] c_{n} \\
& A_{20}=\frac{h}{2} \sum_{n \geq 0}\left[\frac{E_{m} \nu_{m}}{n k_{1}+1}+\frac{E_{m} \nu_{c m}}{(n+1) k_{1}+1}+\frac{E_{c m} \nu_{m}}{k+n k_{1}+1}+\frac{E_{c m} \nu_{c m}}{k+(n+1) k_{1}+1}\right] c_{n} \\
& A_{21}=\frac{h^{2}}{2} \sum_{n \geq 0}\left[E_{m} \nu_{m}\left(\frac{1}{n k_{1}+2}-\frac{1}{2\left(n k_{1}+1\right)}\right)+E_{m} \nu_{c m}\left(\frac{1}{(n+1) k_{1}+2}-\frac{1}{2\left[(n+1) k_{1}+1\right]}\right)\right. \\
& \left.+E_{c m} \nu_{m}\left(\frac{1}{k+n k_{1}+2}-\frac{1}{2\left(k+n k_{1}+1\right)}\right)+E_{c m} \nu_{c m}\left(\frac{1}{k+(n+1) k_{1}+2}-\frac{1}{2\left[k+(n+1) k_{1}+1\right]}\right)\right] c_{n} \\
& A_{22}=\frac{h^{3}}{2} \sum_{n \geq 0}\left[E_{m} \nu_{m}\left(\frac{1}{n k_{1}+3}-\frac{1}{n k_{1}+2}+\frac{1}{4\left(n k_{1}+1\right)}\right)+E_{m} \nu_{c m}\left(\frac{1}{(n+1) k_{1}+3}-\frac{1}{(n+1) k_{1}+2}\right.\right. \\
& \left.+\frac{1}{4\left[(n+1) k_{1}+1\right]}\right)+E_{c m} \nu_{m}\left(\frac{1}{k+n k_{1}+3}-\frac{1}{k+n k_{1}+2}+\frac{1}{4\left(k+n k_{1}+1\right)}\right)+ \\
& \left.+E_{c m} \nu_{c m}\left(\frac{1}{k+(n+1) k_{1}+3}-\frac{1}{k+(n+1) k_{1}+2}+\frac{1}{4\left[k+(n+1) k_{1}+1\right]}\right)\right] c_{n} \\
& A_{30}=\frac{1}{2}\left(A_{10}-A_{20}\right), A_{31}=\frac{1}{2}\left(A_{11}-A_{21}\right), A_{32}=\frac{1}{2}\left(A_{12}-A_{22}\right) \\
& a_{n}=\frac{\nu_{c m}^{n}}{\left(1-\nu_{m}\right)^{n+1}}, c_{n}=\left[\frac{1}{\left(1-\nu_{m}\right)^{n+1}}+\frac{(-1)^{n}}{\left(1+\nu_{m}\right)^{n+1}}\right] \nu_{c m}^{n} \\
& E_{1}=E_{m} h+\frac{E_{c m} h}{(k+1)}, E_{2}=E_{c m} h^{2}\left[\frac{1}{k+2}-\frac{1}{2 k+2}\right] \\
& E_{3}=\frac{E_{m} h^{3}}{12}+E_{c m} h^{3}\left[\frac{1}{k+3}-\frac{1}{k+2}+\frac{1}{4 k+4}\right], D=\frac{E_{1} E_{3}-E_{2}^{2}}{E_{1}\left(1-\nu^{2}\right)}
\end{aligned}
$$

